\title{
On Political and Psychological Essentialisms
}

\section{ANN LAURA STOLER}

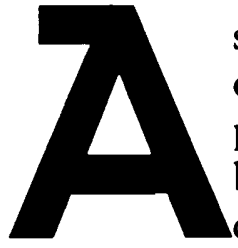

S a cultural anthropologist trained in political economy and ethnographic history, I was schooled to be wary not only of psychological and cognitive assessments of human behavior, but to treat them as analytic strategies that deftly circumvent questions of power and thus represent pernicious substitutes for political analysis. While ingrained fears die hard, people change and I am no exception. My work over the last decade on the making of colonial culture in the 19th-century Dutch East Indies has turned me increasingly to look both at state strategies designed to shape how people affectively distinguish themselves from others in the world, and thus at how attention to sentiment might help us rethink the "political" in political economy.

Working on "an ethnography of the [Dutch] colonial archives" over the last few years, I have been struck by how important folk theories of mental and affective states were to French, Dutch, and British colonial policies. Practitioners of colonial rule were intensively concerned with those nonvisible moral sentiments and internal sensibilities that they took as reasonable criteria to define and secure who was European, who was eligible to be considered "white," and who was not (see Stoler 1996, in press a). My research focus on "mixed-blood" children, "poor whites" (on those interstitial populations poised on politically charged racial divides) repeatedly has pointed to how much the nonvisual and nonsomatic-cultural competencies, personality traits, and psychological dispositions-provided the crucial and changing criteria for racial membership. Thus Hirschfeld's attention to racial nonvisual essence dovetails, if obliquely, in many ways with my own. ${ }^{1}$

My engagement with his arguments are therefore complicated both by our sharp differences in approach and-as should become clear-by some of the common and counterintuitive observations about racial thinking we share. We both have worked for some time on subjects that touch on questions of children and race: he on the cognitive mapping of 
race as it develops and is processed in children's minds, I on the ways in which adult anxieties about children's racial affiliations politically map what was seen as subversive about ambiguous racial milieus and blurred racial categories. ${ }^{2}$ At issue in official documents, private letters, housekeeping manuals, medical guides, and the popular press was whether Dutch-born children and "mixed blood" children of European fathers and Asian mothers reared in the Indies could be counted on to count themselves (in later adulthood) as truly European.

While some of Hirschfeld's and my general themes overlap, our approaches, methodologies, and many of our conclusions do not. What is more striking, and perhaps of more general interest, are those that do. I discuss some of them here because of the persistence with which cognitive and psychological approaches to race (to which he subscribes) and those embraced by social constructionists (what he labels "comparativists," like myself), who have spoken past one another in sustained and counterproductive ways. Thus I direct my comments here not to whether or not Hirschfeld is "right"-whether he adequately "proves" his argument that categories of the mind shape categories of power-but rather what we might gain by entertaining the possibility of a relationship between the two.

Those who study the psychology of race see historical accounts of how collective representations such as "race" are socially constructed as interesting but irrelevant to their implicitly universalizing claims; those who study the social construction of historically specific racisms tend to look upon psychological accounts of racial systems as misleadingly simplistic, ethnocentric, and downright dangerous. Because neither take seriously the other, they/we miss-some might say avoid-the opportunity to engage the compelling and uncomfortable question that Hirschfeld's paper suggests: to what extent and in what ways might it be that certain categories of power acquire the weight and relevance they do in social life because of the ways in which they feed off and build upon categories of the mind?

$\Lambda t$ an intellectual moment when adherence to the constructed, invented, and imagined nature of social categories is deemed fundamental to cultural and political critique, it is easy to misconstrue and therefore dismiss Ilirschfeld's question. Ile is not suggesting that categories of power are determined by categories of the mind, nor that the concept of race is hard-wired in our human brains. Rather, by my reading, he is asking us to engage the possibility that the salience of race as a potent political tool may derive not from the fact that racism is inborn in us, but from the possibility that human beings have a susceptibility or a propensity to classify human kinds in essentialist ways that lend themselves to accommodate racial thinking. 
Is the "success" and tenacity of racialized political systems then contingent in part on the fact that racialization is "easy" to think? And is it "easy to think" because of a more general set of principles that organize our cognitions? Building on the work of the cognitive psychologist Douglas Medin, Hirschfeld argues that psychological essentialism-the epistemological stance that "things that look alike tend to share deeper properties"-provides a "readiness" that makes the essentialist thinking mobilized in the politics of exclusion highly effective. This is not to argue that dominant social groups do not profit from political essentialisms and work to secure them. Nor is it to argue that political essentialisms, such as those inscribed in racialized colonial systems, were seen as "automatically" credible and reasonable simply in virtue of how we as humans are cognitively mapped. Rather, Medin's notion of psychological essentialism and Hirschfeld's claims for a possible relationship between it and categories of power suggest a cognitive readiness to register, remember, and retrieve these sorts of distinctions over others.

Again, it is easy to dismiss the argument if we assume that Hirschfeld is asking us to relegate the political construction and manipulation of racial taxonomies to auxiliary causal status, that is, to see them as mere reflections, unmediated transmissions from our domain-specific brains. But this is not the argument. In fact, Hirschfeld's claims have very little to say to specific racial taxonomies at all. He is more interested in the principles that underlie them. Racial taxonomies vary in time and space. They slice up differently what constitutes a "racial type" and who belongs to which category. He would not argue, I think, that these can be known or understood outside of the political and historical contexts in which they are developed. Nor would he resist a claim I have suggested elsewhere, that racial taxonomies take on specific psychological and political "relevance" in virtue of the ways in which they "fold in" earlier sedimented cultural categories (Stoler 1992). Hirschfeld is addressing not specific racial regimes but rather the racial theory that unites and underwrites them. He is not dismissing the power of political essentialisms but asking us to entertain the proposition that political systems "recruit" what is already available as a "singular, unique category of mind" (p. 64).

Now, whether or not we subscribe to this notion of a "unique category of mind," the fact remains that his questions about how racial theories are formed-about racial epistemologies-are ones that should be of common concern to historians and psychologists. Hirschfeld and I agree that racial thinking builds on a common set of principles about the relationship between the visible and the invisible, between surface appearance and inner essence. Both of us question why neither students of cognition nor those of colonial history have attended more fully to the 
tension between the outer and inner attributes of race. ${ }^{3}$ In his recent book Race in the Making (1996) and my Race and the Education of Desire (1995), we both reject the orthodoxy that racism is primarily a visual ideology dependent on external cues. Based on very different sorts of "evidence" (each of which the other would probably not accept as reliable), we suggest that racial systems are built upon the tension between the internal and external coordinates of race.

The difference lies in how we account for those principles. By Hirschfeld's account, this relationship between the visual and nonvisual derives from how our minds are mapped and what Medin refers to as the "heuristic" appeal of essentialist thinking. My account suggests that this appeal to the nonvisual aspects of race gains its force from another source; namely, from the political effectiveness of a system of social classification that appears fixed, permanent, and commonsensical while it remains porous and pliable. Racial systems depend on a "tactical mobility"; they combine elements of fixity and fluidity in ways that make them both resilient and impervious to empirical, experiential counterclaims. ${ }^{4}$ I suggest then that racisms actually depend on two ways of knowing-one that is visual and supposedly "obvious," and one that is nonvisual, defined by an internal state and for which no evidence is sufficient, no proof is enough.

For some time now, I have been struck by the extent to which French, Dutch, and British architects of colonial social policy sought to identify those "invisible ties" by which membership in the category of homo europeaus was limited and bound. Racial membership was never secured by somatics alone. In fact, I would suggest that racial essentialism is not as we often have assumed, about a fixed notion of essence. Why essentialism works as such a powerful political notion may be, as Hirschfeld claims, because we are cognitively prone to think in those terms. But I would also argue that it "works" because essentialisms confer a "dynamic motility" to racial systems. My premise, contra most accounts of social esssentialism, is that they are not really "fixed" at all. As I have argued elsewhere:

the force of racism is not found in the alleged fixity of visual knowledge, nor on essentialism itself, but on the malleability of the criteria of psychological dispositions and moral sensibilities that the visual could neither definitively secure nor explain. ... A notion of essence does not necessarily rest on immovable parts but on the strategic inclusion of different attributes, of a changing constellation of features and a changing weighting of them. [In press $b]^{5}$

Ilirschfeld argues that the idea of race does not alter under different political environments, an observation he takes as "proof" that the idea of race is independent of political context (p. 69). But why assume that the concept of race is unchanging simply because the term race is constant over time? Are not such terms constantly imbued with new 
political and cultural meaning? What went into determining who was European and "white" in the Indies in 1834 was not the same criteria as that used 100 years later. At both moments, there was some "essence" at issue, some "essence" of what it meant to be European. But the content of that designation was subject to a changing set of power relations, to changes in perception and policy about who should be eligible for membership as European and who should not, and what entitlements and exclusions went along with those classifications. Hirschfeld's claim and my own are not mutually exclusive. Both suggest that we need to think more carefully about the very different spaces that join and disjoin categories of power and categories of the mind.

Finally, as a student of colonial history, I cannot help but question whether race is really and under all circumstances so "easy to think." Hirschfeld seems convinced that adults do not need to teach children race. On the other hand, he would not disagree that adults spend an inordinate amount of time teaching children racism. If race is so "easy to think," why should the architects of colonial policy have expended such time and effort to assure that children did not get their essentialisms wrong? And why were they so convinced that in the absence of a carefully controlled milieu, "even" Dutch born children would prefer to "babble" in Malay, sit on their haunches rather than chairs, undergo a Lamarckian transformation, and "metamorphise" into Javanese? If these racial distinctions were so "easy to think," why did Dutch authorities, civil servants, and civilians in medical guides, pedagogical journals, and the Indies and metropolitan press devote endless pages to the fear that children in the tropics might "lose their Dutch essence" in the proximity of native children and native servants? Why so many classified government reports on the conditions that would educate European children in the Indies into the intangible competencies and psychological sensibilities that would ensure that they would know where they racially belonged? And finally, what were the risks if these were systems of social differentiation for which we as humans are so well prepared?

Cognitive readiness may account for the categories that political systems are prone to adopt, but not the relations of power that bring racial regimes into dominance. Essentialist thinking may, as Hirschfeld argues, ready us to carve social categories at some broad cognitive joints, but it is historically specific relations of power that ensure that cognitive propensities are realized as political ones. We need to attend both to the cognitive ecology in which racial thinking is made possible and to the varied political ecologies in which they are activated, mobilized, and sustained.

According to Hirschfeld, race is a category of power because it is a category of mind. Whether one subscribes to his reasoning or not, the 
question is a critical one for both those concerned with cognition as well as those like myself more interested in what made "state racism" an effective technology of rule in a wide range of colonial contexts, and what makes it so virulent and resilient in modern political systems today.

\section{NOTES}

1. This convergence is not particularly surprising as Lawrence Hirschfeld and I remain partners after two decades.

2. See Stoler 1995, particularly chapter 5 where I discuss this issue at length.

3. See, for example, the otherwise thought-provoking commentaries by David Roediger, Virginia Dominguez, and Loic Wacquant on my paper "Racial Histories and their Regimes of Truth" (in press b), none of which take up what I consider to be a central point of my paper; namely that racisms in part derive their resilience from the ways they play upon the fixity of external attributes and the fluidity of inner essence.

4. See in press $b$.

5. Also see Stoler 1995, where this argument is spelled out in chapter 6 and the epilogue.

\section{REFERENGES ETIED}

Hirschfeld, Lawrence

1996 Race in the Making: Cognition, Culture, and the Child's Construction of Human Kinds. Cambridge: Massachusetts Institute of Technology Press.

Stoler, Ann Laura

1996 A Sentimental Education. In Fantasizing the Feminine in Indonesia. L. Sears, ed.

Pp. 71-91. Durham, NC: Duke University Press.

1992 Sexual Affronts and Racial Frontiers. Comparative Studies in Society and History

34:514-551.

1995 Race and the Education of Desire: Foucault's History of Sexuality and the Colonial

Order of Things. Durham, NC: Duke University Press.

In press a Ethnography in the Colonial Archives: Movements on the Historic Turn. Princeton, NJ: Princeton University Press.

In press b Racial Histories and their Regimes of Truth. Political Power and Social Theory. 